\title{
CORRESPONDENCE
}

\section{Siding Spring}

SIR,--In his letter (Nature, 239, 117; 1972), Professor Geoffrey Burbidge raises a number of issues on most of which I would not presume to comment. His points 3 and 5, however, with the strong implication that Siding Spring Observatory is an "inferior site" do concern this school and should not be allowed to stand. In addition, his assertion that a thorough assessment of observing conditions was not undertaken in choosing the location of the new observatory is not correct. The facts of the situation are as follows.

In the mid-1950s it became apparent that the Mount Stromlo Observatory, 12 miles from Canberra, would begin to lose effectiveness as the city grew. The Australian National University's Department of Astronomy, at that time under Professor B. J. Bok, therefore initiated a programme to find a better site, preferably (for logistical reasons) close to Canberra. A second objective, without the qualification, was to seek the best possible site in Australia for a large telescope. A wide ranging, sitetesting programme was initiated over the period 1958-64, a total of fifteen sites being considered. The staff involved at the Australian National University were Professor B. J. Bok and Drs A. R. Hogg, S. C. B. Gascoigne, A. Rodgers and $B$. Westerlund. Night time cloud cover led to elimination of eleven sites and four years of detailed testing yielded the information shown in Table 1. ment that Siding Spring Observatory was as good a site as was available in Australia at which to build a large telescope. This committee recommended that, if such an instrument was built, it should be at Siding Spring.

Experience at Siding Spring Observatory shows the atmosphere above it to be very transparent, with a visual atmospheric extinction coefficient of some 0.16 magnitudes per unit air mass. The seeing is good-the Australian National University 40 -inch telescope has produced plates showing images as small as 0.5 arc $\mathrm{s}$ diameter. This is a good deal better than our Mt Stromlo Observatory, which at least one experienced US observer has stated to be as good as Mt Wilson.

Although comparisons can be misleading, the evidence available to us is that the Siding Spring Observatory site has characteristics very similar to $\mathrm{Kitt}$ Peak National Observatory in Arizona, where a 150 -inch telescope, also, is in course of erection.

Sites in northern Chile certainly have one major advantage over both Siding Spring Observatory and Kitt Peak National Observatory, in that the usable time appears to be in the range of $80-85 \%$ as compared with some $60 \%$. Chilean sites, however, have some disadvantages. They are remote from centres of learning and technology, they lie in an earthquake zone, and costs of building and operating highly sophisticated equipment are high.

The Australian National University

\begin{tabular}{lcc}
\hline & Table 1 & Results of Site-Testing \\
& $\begin{array}{c}\text { Time usable completely } \\
\text { photometric }(\%)\end{array}$ & $\begin{array}{c}\text { Time usable } \\
\text { spectrophotometric }(\%)\end{array}$ \\
Siding Spring Observatory (NSW) & 43 & 63 \\
Mt Serle (SA Flinders Range) & 45 & 66 \\
Mt Singleton (WA) & 39 & 61 \\
Mt Bingar (NSW) & 44 & 65 \\
Mt Stromlo Observatory (ACT) & 27 & 48 \\
\hline
\end{tabular}

In the event the university, after consideration of these data and other desirable features, chose to site its new observatory on Siding Spring Mountain. Since then the accuracy of the site assessment has been fully confirmed by seven years of operations at the observatory.

Later a local committee, comprising Drs R. Giovanelli (CSIRO), Harley Wood (NSW Government Astronomer), A. Rodgers (ANU) and W. C. Swinbank (CSIRO), who were given access to all the data, made the independent assess- has been delighted to provide sites both for the SRC 48-inch Schmidt telescope and the Anglo-Australian 150-inch telescope at its Siding Spring Observatory.

We believe that work with these two first-class instruments, when they are completed, will make major contributions to astronomy in the future.

Yours faithfully,

E. W. TITTERTON

Research School of Physical Sciences, Australian National University, Canberra, $A C T$

\section{A Counter-homily}

SIR,-On August 4, your leading article "Homilies for the Club of Rome" sounded off with "Earlier this year the organization which calls itself the Club of Rome achieved a notable publishing success...", thus putting the whole thing firmly on a commercial, returnon-capital basis. Now the organization which calls itself, and is, the Club of Rome is not just a bunch of eco-nuts or doomster-nuts. They are mainly people in positions in industry, banking and administration unlikely to be achieved by the soft-headed-Rectors or Vice-Chancellors of one or two Universities, Presidents of the Banque de Bruxelles and the Credit Lyonnais, Presidents or Chairmen of companies like Nippon Electric, Hitachi, Imperial Oil, and the Pulp and Paper Research Institute of Canada.

On the substance of what you adduce against the MIT simulationmodel, Oerlemans, Tellings and de Vries (Nature, 238, 251; 1972) point out that if you modify the MIT model by inserting an optimistic estimate of the effectiveness of discovery of new natural resources, the unfortunate effects of resource exhaustion would be averted. Boyd (Science, 177, 516; 1972) shows that you can achieve an equally happy result if you insert a technology joker, which invents new methods (and, it is implied, delivers the goods on time) just enough to get over any sticky patches. All of which merely shows that the MIT model is a reasonably flexible system, capable of producing a coherent output when fed with a wide variety of inputs -whether garbage or not.

So what would I, as a member of the Club of Rome, bloody but unbowed under Nature's homilies, claim that the MIT team had contributed?

Not predictions of what will happen. They explicitly state that their results are not-repeat not-and they repeat it three or four times-predictions. It is really too obviously a setting up of straw men to criticize the outputs as though they were supposed to be forecasts of what will happen. The nearest they come to this is that they show what could happen if a set of trends, adjusted so that they at least fit the data from the last few decades, continue unmodified into the future. The catastrophes expressed in the MIT graphs are at least rationally conceivable; they are amongst the "possibles" we have to take into consideration. 
Then they have demonstrated a point which people often accept in theory but forget when it comes to practice; that complex systems often react to inputs in unexpected and unintended ways. If you kick a black-box-an outboard motor that won't start, or a TV set-it may do better than before, if it has been designed to have good stability for its main function. But it may do something quite unexpected if its performance has not been well stabilized.

Thirdly, the MIT group have started what will clearly be a long-enduring process of modelling the global situation. Improvements on their Mark I scheme are obviously called for, and some are already in hand by groups associated with the Club of Rome. One AmericanGerman team is developing a model which will "dis-aggregate" the world into three sections: rich capitalist, communist, and the Third World. They will also add another level to the system, namely of goal-setting activities which attempt to control the causal mechanisms so as to attain certain objectives. Another South American group is particularly concerned to distinguish the rich and the poor regions and study the interactions between them.

Beyond these developments, there are three others which seem to me especially desirable: (i) a distinction between material products which are generally agreed to be socially desirable, for example, food and housing and so on for an increasing population, and products which are unnecessary or undesirable (electric toothbrushes, arms); (ii) a recognition of the place of tertiary and quaternary employment (services, information processing, including education); (iii) allowance for unavoidable time lags (how long will it take for increased investment in agriculture or natural resource utilization actually to produce and distribute fertilizers, say, or an infra-structure of roads, bridges and so on?).

There is no reason why such factors should not be built into later versions of world models, and I suggest they almost certainly will be. Nature ends its homily by telling the Club of Rome that it will have to live with some modifications of the Mark I model, exhibiting different properties. I think the remark boomerangs. Nature will find that it has to live with a new field of computermodel exploration of the world system, perhaps comparable in activity to the fields of computer exploration of intelligence and language.

Yours faithfully,

\section{H. WADDINGTON}

Department of Genetics,

University of Edinburgh

\section{Postcards to Nature?}

SIR,-Professor McCrea's suggestion (Nature, 239, 239; 1972) for author credit, refereeing and editing seems likely to generate more editing on your part than it will save, if your correspondents write to point out the many flaws of the idea. May I therefore refrain from criticism and offer instead an alternative scheme?

Basically my suggestion is that journals should publish in full only those papers for which there is a proven demand. The existence of such a demand could be assessed by the initial publication of the abstract alone. Proof of a readership would then be the receipt, within some specified period, of an adequate volume of requests for further details; the time allowed would clearly vary from subject to subject and journal to journal. If the number of requests received were large enough the full paper would be refereed, edited and published as at present, thus taking its deserved place in the scientific literature; otherwise it would be the responsibility of the author to send photocopies or the like of his manuscript to those few people who had requested details of the work.

In some subjects the delay involved in the process described above would be undesirable. In most of these subjects, however, there will be considerable personal contact between those engaged in the field and it should be possible for an author to demonstrate the existence of a readership when submitting his manuscript to the journal; the paper could then be published forthwith.

Some people may object that many of the papers published in Nature are already so short that their abstracting would cause difficulty. Logically, however, this problem should be met by requiring very short abstracts with which to test for a readership; perhaps these could be published as "Postcards to Nature"?

Both Professor McCrea's suggestion and my own are based on the assumption that scientists currently write too much about too little, thus clogging the literature with print few wish to read; in this case one may well ask whether the solution does not lie in more (and more stringent) refereeing rather than in less!

\section{Yours faithfully, RAYMOND J. O'CONNOR}

Department of Zoology,

The Queen's University of Belfast, Belfast BT7 1 NN

\section{HOW TO BUY NATURE}

Volumes start in January, March, May, July, September and November, but subscriptions may begin at any time.

The direct postal price per subscription is:

12 MONTHS* (52 issues per title)

\begin{tabular}{|c|c|c|}
\hline & $\begin{array}{c}\text { Surface mail } \\
\text { UK and } \\
\text { worldwido }\end{array}$ & $\begin{array}{l}\text { U.S.A. and } \\
\text { Canada }\end{array}$ \\
\hline Nature (Friday) & $\mathbf{f 1 4}$ & $\$ 48$ \\
\hline $\begin{array}{l}\text { Nature }+ \\
\text { Nature Physical Science }\end{array}$ & $£ 24$ & $\$ 83$ \\
\hline $\begin{array}{l}\text { Nature }+ \\
\text { Nature New Biology }\end{array}$ & $£ 24$ & $\$ 83$ \\
\hline All three editions & $£ 29.50$ & $\$ 108$ \\
\hline Annual Index & $£ 1$ & $\$ \mathbf{3}$ \\
\hline
\end{tabular}

* Rates for shorter periods pro rata (minimum three months) (Charge for delivery by air mail on application)
Editorial and Publishing Offices of NATURE

MACMILLAN JOURNALS LIMITED 4 LITTLE ESSEX STREET, LONDON WC2R 3LF

Telephone Number: 01-836 6633. Telegrams: Phusis London WC2R 3LF Telex 262024

711 NATIONAL PRESS BUILDING WASHINGTON DC 20004 Telephone Number : 202-737 2355. Telex 64280 Subscription Department MACMILLAN JOURNALS LIMITED

BRUNEL ROAD, BASINGSTOKE, HANTS

Telephone Number: Basingstoke 29242

American display advertisements

NATURE SCIENTIFIC PUBLICATIONS INC

711 NATIONAL PRESS BUILDING WASHINGTON DC 20004

All other display advertisements PETER R. KAVANAGH

MACMILLAN JOURNALS LIMITED

4 LITTLE ESSEX STREET, LONDON WC2R 3LF Classified advertisements

T. G. SCOTT \& SON, LIMITED

1 CLEMENT'S INN, LONDON WC2A 2ED

Telephone: 01 -242 6264/01-405 4743

Telegrams: Textualist London WC2A 2ED

Registered as a newspaper at the Post Office

Copyright (C) Macmillan Journals Limited, October 131972 